\title{
高性能锂-硫电池用复合正极的构造与粘结剂
}

\author{
伍英蕾杨 军* 王久林等丽燕娜 \\ (上海交通大学化学工程系, 上海 200240)
}

\begin{abstract}
摘要：采用球磨混合及热处理方法制备了含有多壁碳纳米管(MCNTs)的硫基复合正极材料,利用 $\mathrm{X}$ 射线衍 射 (XRD) 和扫描电子显微镜 (SEM) 测定材料的结构和形貌, 较系统地研究了 MCNTs 含量和粘结剂种类对硫基 复合正极容量、循环稳定性和自放电行为等的影响. 结果表明: MCNTs 的合适含量为 $5 \%-8 \%$ ( $w$, 质量分数), 以 水性粘结剂环糊精制备的硫基复合正极电化学性能最佳. 锂-硫电池在常温和半充电状态下放置 30 天几乎没有 自放电; 当电流倍率为 $0.1 C$ 时, $\beta$-环糊精为粘结剂的正极初始充电容量为 $687.7 \mathrm{mAh} \cdot \mathrm{g}^{-1}, 100$ 次循环以后可逆 容量为 $623.8 \mathrm{mAh} \cdot \mathrm{g}^{-1}$, 容量保持率达 $90.7 \%$.
\end{abstract}

关键词： 锂-硫电池； 硫基正极；多壁碳纳米管； 水性粘结剂； 环糊精 中图分类号: 0646.21

\section{Composite Cathode Structure and Binder for High Performance Lithium-Sulfur Battery}

\author{
WU Ying-Lei YANG Jun* WANG Jiu-Lin YIN Li-Chao NULI Yan-Na \\ (Department of Chemical Engineering, Shanghai Jiaotong University, Shanghai 200240, P. R. China)
}

\begin{abstract}
Ball milling in combination with heat treatment was used to prepare sulfur-based composite cathode materials incorporating multi-walled carbon nanotubes (MCNTs) for Li-S battery. The structure and morphology of the as-prepared cathode materials were characterized by X-ray diffraction (XRD) and scanning electron microscopy (SEM). The effect of MCNT content and binder type on the capacity, cyclability and self-discharge behavior of a sulfur-based cathode were systematically investigated. Results show that the appropriate amount of MCNTs is $5 \%-8 \%$ ( $w$, mass fraction) and the use of $\beta$-cyclodextrin as a water-soluble binder to fabricate the cathode results in the best electrochemical performance. When the Li-S battery was half charged at room temperature, there was almost no selfdischarge during storage for $30 \mathrm{~d}$. The charging capacity was $687.7 \mathrm{mAh} \cdot \mathrm{g}^{-1}$ during the 1 st cycle and $623.8 \mathrm{mAh} \cdot \mathrm{g}^{-1}$ during the 100th cycle for the cathode at a current rate of $0.1 \mathrm{C}$. Therefore, $90.7 \%$ of the capacity was retained.
\end{abstract}

Key Words: Li-S battery; Sulfur-based cathode; MCNTs; Water-soluble binder; Cyclodextrin

常温下元素硫与锂的电化学反应具有可逆性. 因此, 硫作为二次锂电池正极材料具有理论比容量 高, 价格低廉和安全无毒等优点 ${ }^{[1-2]}$, 应用前景广阔. 然而, 硫基电极依然存在许多缺点 ${ }^{[3-7]}$, 制约着锂-硫 电池的实用化. 首先, 硫基电极中的硫活性颗粒导电 性差, 利用率低, 并且随着电化学循环的进行, 电极
结构易溶胀、坍塌和剥落致使硫的利用率越来越低; 其次, 在电化学循环过程中放电产物 $\mathrm{Li}_{2} S_{y}(y \geqslant 4)$ 在 电解液中的溶解造成电池自放电, 也使电解液的粘 度增加, 离子扩散受阻, 影响电极的循环性能. 再次, 硫基电极最常使用聚偏氟乙烯(PVDF)或者聚环氧 乙稀(PEO)作为粘结剂, 但是这些粘结剂在有机溶液

Received: July 27, 2009; Revised: October 12, 2009; Published on Web: December 16, 2009.

*Corresponding author. Email: yangj723@sjtu.edu.cn; Tel: +86-21-54747667.

The project was supported by the National Key Basic Research Program of China (973) (2007CB209700) and Shanghai Key Basic Research Fund, China (07JC14024).

国家重点基础研究发展规划项目(973) (2007CB209700)和上海市基础研究重点基金(07JC14024)资助项目 
中易溶胀 ${ }^{[8-11]}$, 使粘结性能降低, 电极的导电性变差. 因此, 近几年主要围绕改善硫的导电性和电化学可 逆性开展研究. 在材料结构上, 首先考虑是将单质硫 吸附在高导电的多孔碳母体中 ${ }^{[12-16]}$, 其次是采用有 机硫化物 ${ }^{[17-19]}$, 再则是制备含硫复合材料 ${ }^{[20-21]}$. 这些 新型材料结构或多或少提高了电极的循环稳定性, 硫基活性材料的容量高达约 $800 \mathrm{mAh} \cdot \mathrm{g}^{-1}$. 此外, 使 用无污染、高粘性的粘结剂来稳定电极结构, 提高电 极的循环性能也是近期研究的方向 ${ }^{[22-27]}$.

我们先前制备的硫基导电复合正极材料具有 $700 \mathrm{mAh} \cdot \mathrm{g}^{-1}$ 以上的高容量和较好的循环稳定性 ${ }^{[20]}$. 但从材料粉末结构看, 数百纳米的一次颗粒团聚成 微米级的二次大颗粒, 这些大颗粒一方面增加了锂 离子在固相中的扩散距离, 不利于反应的进行; 另一 方面, 在充放电过程中的体积变化会使大颗粒离解 成小颗粒, 使部分活性颗粒的电接触变差. 本文尝试 通过在反应物中掺人少量纳米碳纤维抑制产物的颗 粒长大和团聚. 同时高导电的 MCNTs 有望将反应 颗粒相互连接起来, 形成好的导电网络, 以便提高电 极的工作稳定性. 本文研究和比较了传统与新型粘 结剂对硫基正极电化学性能的影响, 并探讨了相关 作用机理.

\section{1 实验部分}

\section{1 材料制备}

将聚丙烯腈(PAN, 密度 $1.184 \mathrm{~g} \cdot \mathrm{cm}^{-3}$, 美国SigmaAldrich 公司), 升华硫(CP, 国药化学试剂集团)和多 壁碳纳米管(MCNTs, 直径 10-30 nm, 深圳市比尔科 技发展有限公司)按一定的质量比(1:6: $x, 0 \leqslant x<1)$ 球 磨混合均匀后, 装载于石英舟中, 将石英舟移人石英 管, 在流动的氞气气氛保护下, 在 $320{ }^{\circ} \mathrm{C}$ 加热 $7 \mathrm{~h}$, 得 到黑色的含硫复合材料. 热处理过程中, 有硫化氢气 体逸出, 多余的升华硫随流动的氩气一起排出.

\section{2 材料表征}

样品的物相结构通过 X 射线衍射仪 (XRD, D/ max-2200/PC, Japan Rigaku Corporation)测定. 采用 $\mathrm{Cu} K_{\alpha}$ 辐射源, 波长为 $0.15406 \mathrm{~nm}$, 扫描速率为 $5\left(^{\circ}\right)$ • $\mathrm{min}^{-1}$. 样品的形貌分析是先将样品放人无水乙醇中, 用超声波分散一定时间, 取少量分散液滴在盖玻片 上, 然后在扫描电子显微镜 $(S E M, S-2150$, Hitachi Corp., Japan)下进行形貌观察. 采用碳硫分析仪(HCS$040 \mathrm{G}$, 中国上海德凯仪器公司)检测硫含量, 本文中 使用的不含 MCNTs 的复合材料硫含量约为 $45.6 \%$ $(w)$, 含有 $5 \%(w)$ MCNTs 的复合材料硫含量约为 $42.2 \%$.

\section{3 硫基复合正极的制备}

将制得的硫基复合活性材料, $\beta$-环糊精(简称为 HHJ, 国药化学试剂集团)粘结剂与 Super P 导电剂 按质量比 80:10:10 混合, 加人适量蒸馏水作为分散 剂, 先超声波处理 $30 \mathrm{~min}$, 超声波频率为 $100 \mathrm{kHz}$, 然后加热至 $40{ }^{\circ} \mathrm{C}$ 并磁力摚拌 $4 \mathrm{~h}$, 接着将三者混合 均匀的浆料涂覆在铝簿上, $80{ }^{\circ} \mathrm{C}$ 下真空干燥 $2 \mathrm{~h}$, 随 后用 $\Phi 12.5 \mathrm{~mm}$ 的冲头冲成圆形极片, 在 $1 \mathrm{MPa}$ 的 压强下压片后得到硫基正极片. 电极涂层薄膜的厚 度约为 $25 \mu \mathrm{m}$.

参照上述方法依次制备以明胶(简称为 $\mathrm{MJ}$, Bloom160, 勃氏粘度 12)、PVDF 和聚四氟乙烯 (PTFE) 为粘结剂的电极. 只是 PVDF 的分散剂是 $N$ 甲基吡咯烷酮(NMP, AR, 国药化学试剂集团), 并且 以 PVDF 和 PTFE 为粘结剂的电极浆料在磁力摚拌 过程中不需要加热.

\section{4 电化学性能测试}

将采用 1.3 节方法所制的四种粘结剂正极片转 移到氩气手套箱(UNLAB, 德国 M.Braun 公司), 以 金属锂为对电极制成实验扣式电池(CR2016), 电解 液为 $1 \mathrm{~mol} \cdot \mathrm{L}^{-1} \mathrm{LiPF}_{6} / \mathrm{EC}: \mathrm{DMC}$ (体积比 1:1, EC: 碳酸 乙烯酯, DMC: 二甲基碳酸酯), 隔膜为 ENTEK ET20-26 PE. 将装配好的电池静置 $8 \mathrm{~h}$ 以后, 在电池 测试系统(Land CT2001A, 武汉金诺电子有限公司) 上进行充放电和循环性能测试. 测试温度为 $25{ }^{\circ} \mathrm{C}$, 充放电电流倍率为 $0.1 C$ 和 $2 C$, 充放电电压范围为 1-3 V(vs $\left.\mathrm{Li} / \mathrm{Li}^{+}\right)$. 循环伏安实验采用电化学工作站 (CHI604, 上海辰华仪器公司)进行测试, 扫描速率为 $0.2 \mathrm{mV} \cdot \mathrm{s}^{-1}$. 采用交流阻抗仪(SI-1287, 1260 系统, 英 国 Solartron Metrology 公司)测定电极的电化学阻抗 谱, 测试频率范围为 $10^{-1}-10^{5} \mathrm{~Hz}$, 微扰电压为 $5 \mathrm{mV}$. 本文所指的比容量是以整个复合材料的质量计算而 得.

\section{2 结果与讨论}

\section{1 材料结构和形貌分析}

图 1 为加人 MCNTs 前后合成材料的 XRD 谱 图. 样品在 $25^{\circ}$ 附近有宽的衍射峰, 但未见硫元素特 征衍射峰, 有关文献对该复合材料的可能结构已经 进行了分析和推测 ${ }^{[20-21]}$. 加人 MCNTs 后的衍射图谱 在 $26.6^{\circ}$ 出现了一个尖锐的碳衍射峰, 证明 MCNTs 


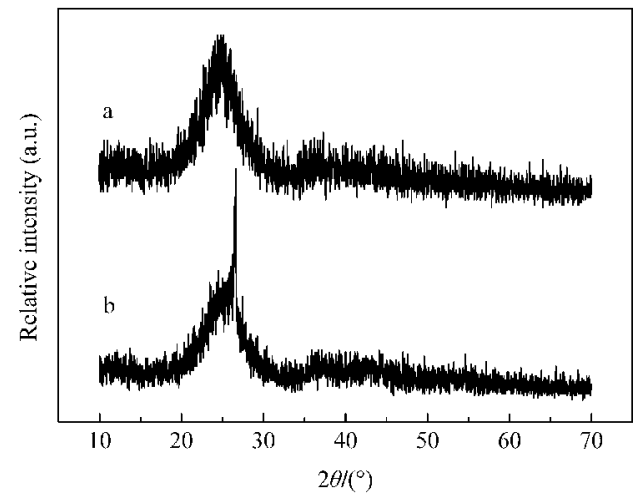

图 1 加入 MCNTs 前(a)后(b)含硫复合材料的 XRD 衍射图 Fig.1 XRD patterns for sulfur-based composite materials before (a) and after (b) incorporating MCNTs

中的碳为 R 心六方的晶体结构.

图 2 为加人 MCNTs 前后含硫复合材料的 SEM 照片. 对比复合前 (a) 与复合后 (b) 的颗粒状态 可以看出, 加人 MCNTs 之后, 粉末颗粒的团聚效应 减轻, 而且 MCNTs 较均匀地贯穿于纳米活性颗粒 之间, 形成良好的结构骨架和导电网络.
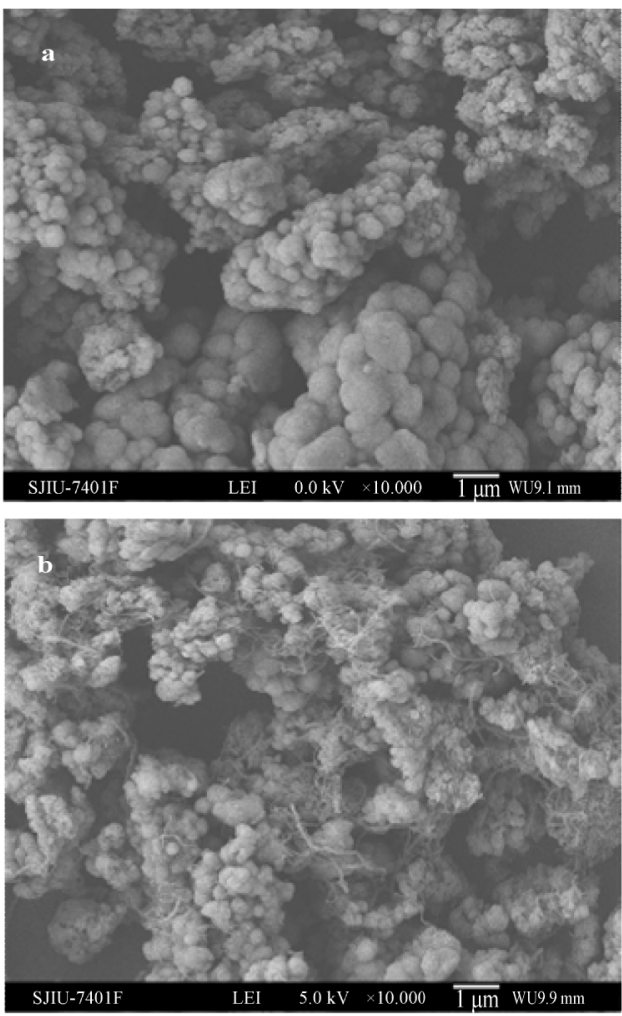

图 2 加入 MCNTs 前(a)后(b)含硫复合材料的 SEM 图 Fig.2 SEM images for sulfur-based composite material before (a) and after (b) incorporating MCNTs

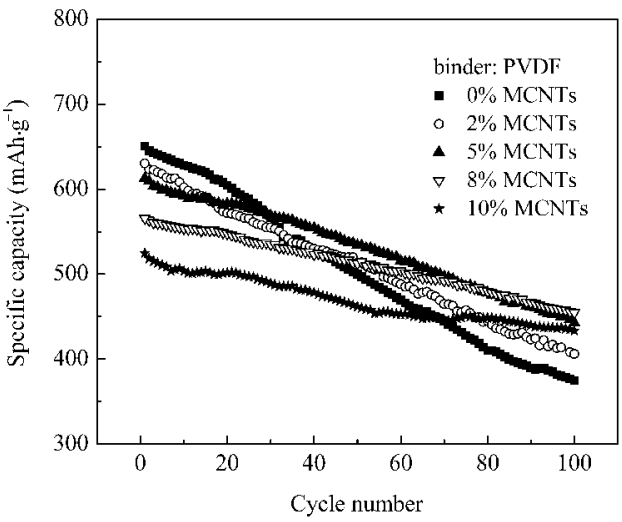

图 3 MCNT 含量 $(w)$ 对材料电化学性能的影响

Fig. 3 Effect of the MCNT content $(w)$ on the electrochemical performance of the materials PVDF: polyvinylidenefluoride; MCNTs: multi-walled carbon nanotubes

\section{2 纳米碳管复合改性}

以传统的 PVDF 作为粘结剂, 采用 $0.1 C$ 的充放 电倍率考察 MCNTs 含量对材料电化学循环性能的 影响, 结果见图 3 和表 1. 由于 MCNTs 本身在 1-3 $\mathrm{V}$ 内没有明显的储锂容量, 复合 MCNTs 将减少电 极的比容量, 但可以改善反应相的导电性和电极结 构稳定性. 原始材料的初始充电容量为 $650.4 \mathrm{mAh}$. $\mathrm{g}^{-1}, 100$ 次循环后容量下降到 $374.4 \mathrm{mAh} \cdot \mathrm{g}^{-1}$, 容量 保持率为 $57.6 \%$. 随着 MCNTs 的不断加人, 材料的 初始容量逐渐下降, 但循环性能却明显改善. 当 MCNTs 在复合物中的含量达到 $10 \%(w)$ 时, 初始充 电容量下降到 $524.6 \mathrm{mAh} \cdot \mathrm{g}^{-1}, 100$ 次循环后容量为 $433.2 \mathrm{mAh} \cdot \mathrm{g}^{-1}$, 容量保持率达 $82.6 \%$. 兼顾容量和稳 定性的双重因素, 复合材料中较合适的 MCNT含量 为 5\%-8\% $(w)$, 在电极的初始容量下降较少的前提 下获得了良好的循环稳定性.

\section{3 粘结剂对电极性能的影响}

\subsection{1 循环性能和倍率特性}

表 1 不同 MCNT 含量的材料第 1 和第 100 次充电容量和 容量保持率

Table 1 The 1st and 100th charge capacity and capacity retention for the materials containing various MCNT content

\begin{tabular}{cccc}
\hline $\begin{array}{c}w(\mathrm{MCNTs}) \\
(\%)\end{array}$ & $\begin{array}{c}\text { Capacity (1st) } \\
\left(\mathrm{mAh} \cdot \mathrm{g}^{-1}\right)\end{array}$ & $\begin{array}{c}\text { Capacity }(100 \text { th }) \\
\left(\mathrm{mAh} \cdot \mathrm{g}^{-1}\right)\end{array}$ & $\begin{array}{c}\text { Capacity } \\
\text { retention }(\%)\end{array}$ \\
\hline 0 & 650.4 & 374.4 & 57.6 \\
2 & 630.2 & 405.9 & 64.4 \\
5 & 612.8 & 442.9 & 72.3 \\
8 & 565.5 & 454.5 & 80.4 \\
10 & 524.6 & 433.2 & 82.6 \\
\hline
\end{tabular}



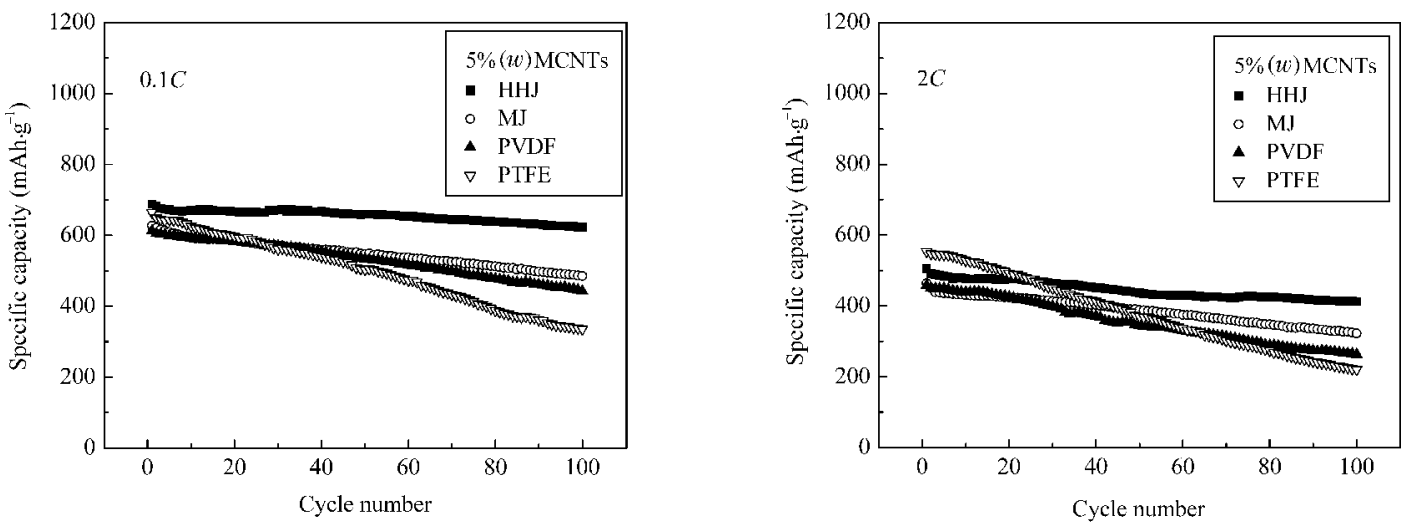

图 4 不同电流倍率下四种粘结剂对充电循环稳定性的影响

Fig.4 Effect of four kinds of binders on the cycle performance at various current rates HHJ: cyclodextrin; MJ: gelatin; PTFE: polytetrafluoroethylene

采用 $\mathrm{MCNT}$ 含量为 $5 \%(w)$ 的硫基正极复合材 料, 在 $0.1 C$ 与 $2 C$ 充放电倍率下考察不同粘结剂对 电极循环性能的影响. 图 4 显示了用四种不同粘结 剂制备的电极前 100 次循环的充电容量变化曲线, 表 2 给出了相应的第 1 次与第 100 次的容量变化数 值及 100 次循环的容量保持率. 从曲线和列表可以 看出: 在两种不同的电流倍率下, 四种粘结剂由好 变差的次序依次是环糊精、明胶、PVDF 和 PTFE. 在 $0.1 C$ 电流倍率下, 以环糊精为粘结剂的电极有最高 的初始充电容量和最好的电化学可逆性; 在 $2 C$ 电 流倍率下, 环糊精的循环稳定性依然最为优异, 但是 初始容量却没有 PTFE 粘结剂电极高, 可见, PTFE 相对于其它三种粘结剂, 电极的倍率性能最好, 但循 环性能最差. 以环糊精作为粘结剂的电极无论是在 小电流还是大电流倍率下充放电, 都具有较好的循 环性能, 特别是在 $0.1 C$ 小电流倍率下, 100 次循环 后容量保持率达 $90.7 \%$.

环糊精和明胶作为两种新型的水性粘结剂在循 环稳定性方面显著优于传统的 PVDF 和 PTFE, 本 文进一步考察这两种粘结剂制作电极的充放电特

\section{表 2 不同粘结剂制作的正极第 1 和第 100 次的充电容量 和容量保持率}

Table 2 The 1st and 100th charge capacity and capacity retention for cathodes containing different binders

\begin{tabular}{cccc}
\hline Binder & $\begin{array}{c}\text { Capacity (1st) } \\
\left(\mathrm{mAh} \cdot \mathrm{g}^{-1}\right)\end{array}$ & $\begin{array}{c}\text { Capacity }(100 \text { th) } \\
\left(\mathrm{mAh} \cdot \mathrm{g}^{-1}\right)\end{array}$ & $\begin{array}{c}\text { Capacity retention } \\
(\%)\end{array}$ \\
\hline HHJ & $68.1 C / 2 C)$ & $(0.1 C / 2 C)$ & $(0.1 C / 2 C)$ \\
MJ & $626.6 / 463.7$ & $485.4 / 322.0$ & $97.5 / 69.4$ \\
PVDF & $612.8 / 457.9$ & $442.9 / 263.6$ & $72.3 / 57.6$ \\
PTFE & $664.4 / 553.2$ & $335.7 / 220.2$ & $50.5 / 39.8$ \\
\hline
\end{tabular}

性. 图 5 显示了环糊精和明胶粘结剂电极的典型(第 10 次)充放电曲线. 可以看出, 以明胶为粘结剂的电 极不仅容量较低, 而且充放电电压极化更大. 图 6 的 循环伏安特性显示环糊精为粘结剂的电极氧化还原 峰的强度均要大于明胶体系, 并且峰电压差更小. 这 进一步证实, 使用环糊精为粘结剂的电极具有更高 的电化学活性和可逆性.

\subsection{2 自放电行为}

已有的研究表明, 锂-硫电池的自放电主要是多 硫化锂从正极溶解到电解液中造成的, 而在完全充 电和放电的情况下正极中几乎不存在多硫化物. 通 常, 半充电或半放电状态下多硫化锂含量较高, 更易 显现电池的自放电现象. 为了考察电极粘结剂对自 放电的影响, 将含有四种粘结剂的电池在电流倍率 为 $0.1 C$, 电压范围为 $1-3 \mathrm{~V}$ 下进行充放电, 直到第 11 和 12 次充放电曲线完全吻合, 表明电池处在稳 定的充放电状态. 在第 13 次放电后再充电, 当电池

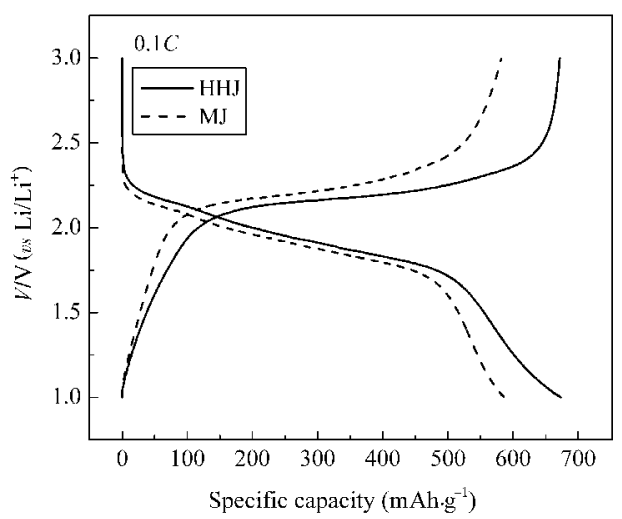

图 5 环糊精和明胶为粘结剂的电极第 10 次充放电曲线

Fig.5 The 10th charge-discharge curves of the electrodes using cyclodextrin and gelatin as binder 


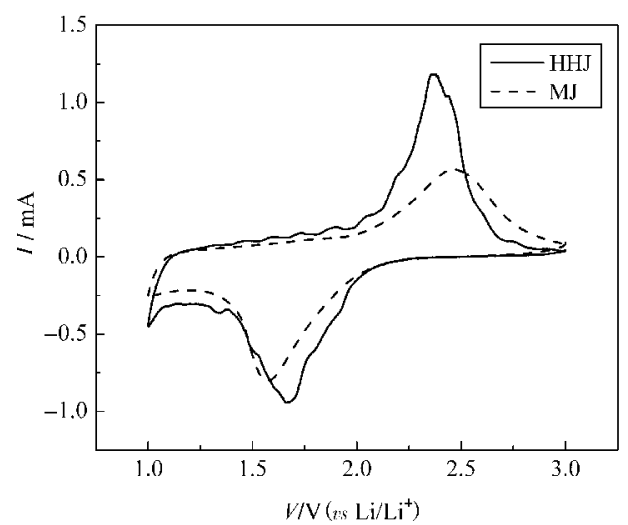

图 6 环糊精和明胶为粘结剂的电极第 2 周循环伏安曲线

Fig.6 CV curves of the electrodes using cyclodextrin and gelatin as binder in the 2 nd cycle scan rate: $0.2 \mathrm{mV} \cdot \mathrm{s}^{-1}$

的充电容量达到放电容量一半的时候停止充电, 在 开路和常温状态下静置 $30 \mathrm{~d}$. 再将电池接人充放电 系统继续充电, 观察电池的自放电情况. 实际上, 这 里所反映的是电池在静置阶段锂离子从正极的溶出 程度. 结果见图 7, 以环糊精作为粘结剂的电池几乎 没有自放电现象, 一个月后容量无衰减; 以明胶、 PVDF 和 PTFE 作为粘结剂的电池自放电率分别为 $2.07 \% 、 3.61 \%$ 和 $6.26 \%$. 环糊精粘结剂的优势极为明 显.

\subsection{3 交流阻抗特性}

图 8 为含不同粘结剂电极组装的电池经过第 1 次和第 50 次循环在 $2 \mathrm{~V}$ 电压下测得的交流阻抗谱.
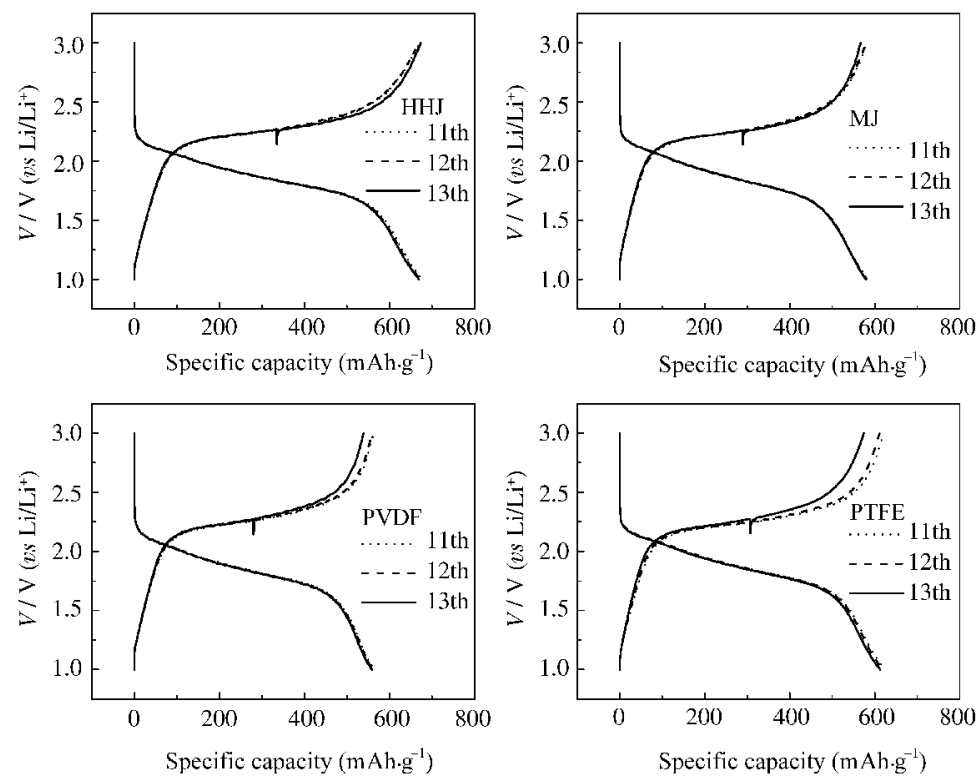

图 7 不同电极粘结剂的电池半充电静置 30 天的自放电行为

Fig.7 Self-discharge behavior of the half-charged cells using different electrode binders during $30 \mathrm{~d}$ 

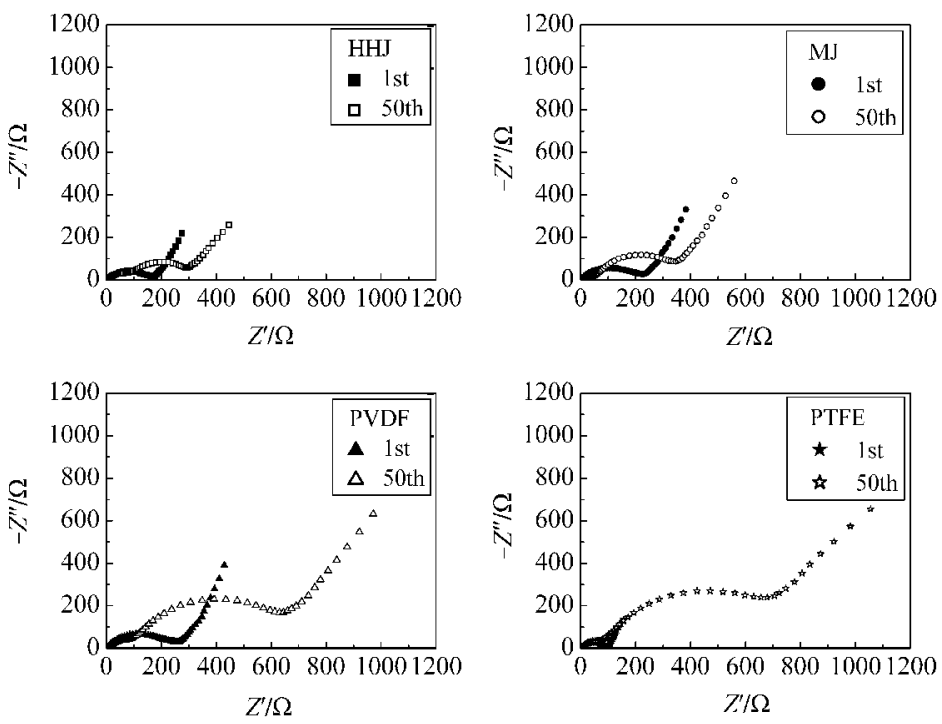

图 8 不同电极粘结剂的电池在第 1 次和 50 次循环时的交流阻抗谱图

Fig.8 Impedance spectra of cells based on various electrode binders at the 1st and 50th cycles

应发生在约 $0.73 \mathrm{~V}\left(v s \mathrm{Li} / \mathrm{Li}^{+}\right)$, 所以, PTFE 的分解变 质可以被排除. 虽然 PVDF 在电极中的分布状况与 另外两种水性粘结剂相似, 但 PVDF 在有机电解液 中溶胀严重 ${ }^{[10-11]}$, 加上电极的体积效应, 会使粘结强 度减弱, 影响电极的结构和导电稳定性. 相对来说, 环糊精和明胶两种水性粘结剂用于硫基正极具有明 显优势, 尤其是环糊精的效果最好, 其可能的作用机 制进一步讨论如下.

\section{4 粘结剂的作用机理初探}

环糊精和明胶表现出的电化学性能差异可能与 各自的分子结构有关 ${ }^{[31]}$. 环糊精是淀粉的酶解产物, 属葡萄糖分子聚合物. 本文所使用的 $\beta$-环糊精由 7 个葡萄糖单位通过 $\alpha-1,4$ 糖苷键首尾连接而成. 其

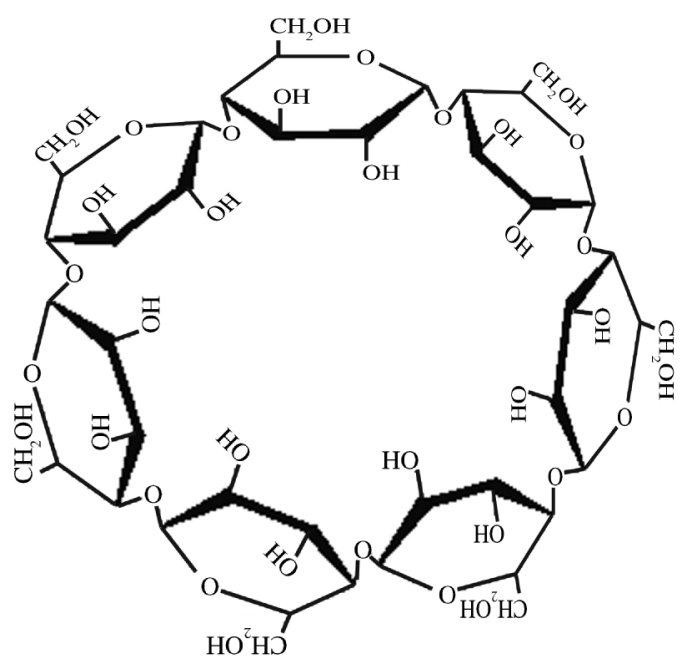

图 $9 \boldsymbol{\beta}$-环糊精的分子结构图

Fig.9 Molecular structure of $\beta$-cyclodextrin
分子呈上宽下窄、两端开口、中空的雉形筒状结构 (见 图 9), 腔内部呈相对疏水性,而所有亲水性的羟基 都在分子外部, 因此表现出内侧疏水,外侧亲水的特 性. 可以使疏水物质形成水溶性的包含络合物, 增加 被包含物质的稳定性. 明胶是胶原蛋白质的水解产 物, 属氨基酸分子聚合物, 具有链状结构. 而且, 两者 所含的极性基团类型也不同.

Sun 等 ${ }^{[24-27]}$ 尝试过在锂-硫电池中使用明胶作为 粘结剂制备了一种硫基正极, 该电极比 PEO 粘结剂 电极有着更高的容量和更好的循环性能. 主要原因 在于明胶的高粘附能力保证了电极结构在电化学 循环过程中的稳定性, 并且与集流体粘接紧密不剥 落 ${ }^{[32]}$; 其次, 明胶的分散性好 ${ }^{[33]}$, 能减轻循环过程中 活性物质的团聚; 再则, 亲水性的明胶不溶于有机 电解液, 在电池中不溶胀, 保持了电极结构的稳定. 一般认为这些优良的特性与明胶分子上的极性基 团一 $\mathrm{COOH}$ 和一 $\mathrm{NH}_{2}$ 有关. 这两种极性基团的存在 使得明胶充当一种良好的粘结剂、分散剂与稳定剂, 在硫基正极中发挥作用.

基于本文实验结果, 环糊精要优于明胶, 可以作 如下推测: 单个 $\beta$-环糊精含有 21 个极性羟基, 而环 糊精的相对分子量为 1135 , 那么单位质量的环糊精 上就具有 $21 / 1135$ 个羟基极性基团. 明胶是由氨基 酸分子聚合而成, 氨基酸的平均相对分子量为 128 , 大多数氨基酸上只连有一个极性羧基和一个极性氨 基, 氨基酸聚合形成多肽链的过程中羧基(- $\mathrm{COOH})$ 和氨基 $\left(-\mathrm{NH}_{2}\right.$ ) 缩合形成酰胺键 ( $\left.-\mathrm{CO}-\mathrm{NH}-\right)$, 会 


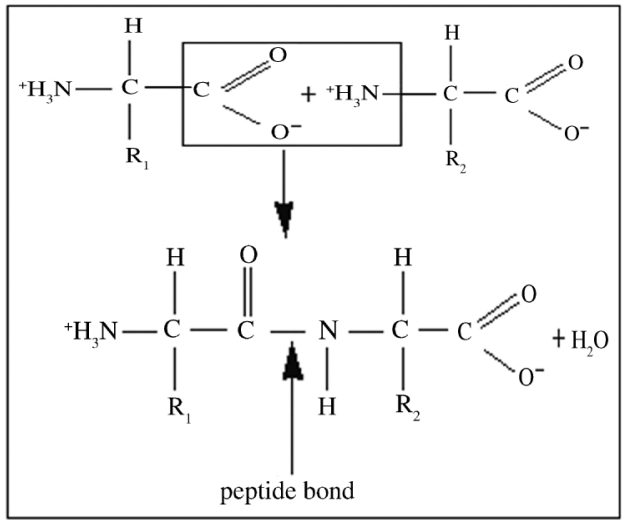

图 10 肽键的形成过程示意图

Fig.10 Schematic diagram of the formation of peptide bond

损耗大部分的羧基和氨基, 只留下肽链两端的一个 羧基和一个氨基, 以及肽链内部极少数特殊氨基酸 $\mathrm{R}$ 基团上携带的少量羧基或氨基(见图 10). 明胶的 平均相对分子量在 30000 左右, 那么单位质量的明 胶上就只剩下少量的自由极性基团 (羧基和氨基), 并且明胶的分子量越大, 极性越小. 因此, 单位质量 的环糊精上所携带的极性基团数目要远大于明胶, 表现在物理特性上就是更好的分散性、粘结性和稳 定性. 加上环糊精分子呈现出的中空微囊结构具有 更好的包合效果, 这些可能是环糊精作为粘结剂更 具优势的原因.

\section{3 结 论}

加人 5\%-8\%(w)的 MCNTs 能减轻硫基纳米颗粒 的团聚并改善复合正极材料的导电性, 在初始容量 稍有下降的情况下显著改善了电极的循环性能. 使 用环糊精或明胶作为电极的粘结剂可以在小电流倍 率下获得比传统的 PVDF 或 PTFE 粘结剂更高的容 量和更好的循环稳定性. 在 $0.1 C$ 倍率下充放电, 环 糊精为粘结剂的正极的初始充电容量为 687.7 $\mathrm{mAh} \cdot \mathrm{g}^{-1}, 100$ 次循环后为 $623.8 \mathrm{mAh} \cdot \mathrm{g}^{-1}$, 容量保持 率达 $90.7 \%$. PTFE 为粘结剂的正极虽然循环性能最 差, 但是却有着最好的初期循环倍率性能, 这是由于 粘结剂不同的物理特性造成的. 环糊精、明胶和 PVDF 粘结剂溶于各自的溶剂, 在活性颗粒表面能 形成完整的粘结剂包覆层, 而 PTFE 粘结剂以纳米 颗粒分散在电极中, 在较低压强下的压片过程难以 使纳米微粒有效延展和丝化, 电解液能与部分活性 颗粒直接接触, 改善了界面反应动力学. 但活性颗粒
的体积变化效应、PTEF 相对较差的分散均匀性和 与 PVDF 类似的溶胀性可能使其电极结构松动和导 电性变差. 因此, 表现出 PTFE 为粘结剂的电极有高 倍率充放电能力和差的循环性能.

环糊精作为一种新型的水性粘结剂在锂-硫电 池中表现出了优良的电化学性能, 可能与分子内部 众多的羟基极性基团和特殊的中空微囊分子结构有 关. 其更深层次的分子作用机理还有待进一步研究. 作为一种价廉无毒的水溶性粘结剂, 环糊精在锂-硫 电池中具有极大的应用潜力.

\section{References}

1 Yamin, H.; Peled, E. J. Power Sources, 1983, 9(3): 28

2 Akridge, J. R.; Mikhaylik, Y. V.; White, N. Solid State Ionics, 2004, 175(1-4): 243

3 Kolosnitsyn, V. S.; Karaseva, E. V. Russ. J. Electrochem., 2008, 44(5): 506

4 Lee, Y. M.; Choi, N. S.; Park, J. H.; Park, J. K. J. Power Sources, 2003, 119(Sp. ISS.SI): 964

5 Kim, S.; Jung, Y.; Lim, H. S. Electrochim. Acta, 2004, 50: 889

6 Zhu, X. J.; Wen, Z. Y.; Gu, Z. H.; Lin, Z. X. J. Power Sources, 2005, 139(1-2): 269

7 Choi, Y. J.; Chung, Y. D.; Baek, C. Y.; Kim, K. W.; Ahn, H. J.; Ahn, H. J. J. Power Sources, 2008, 184(2): 548

8 Cheon, S. E.; Cho, J. H.; Ko, K. S.; Kwon, C. W.; Chang, D. R.; Kim, H. T.; Kim, S. W. J. Electrochem. Soc., 2002, 149(11): A1437

9 Montoro, L. A.; Rosolen, J. M. Solid State Ionics, 2003, 159 (3-4): 233

10 Zhang, S. S.; Jow, T. R. J. Power Sources, 2002, 109(2): 422

11 Chen, L. B.; Xie, X. H.; Xie, J. Y.; Wang, K.; Yang, J. J. Appl. Electrochem., 2006, 30(10): 1099

12 Wang, J. L.; Yang, J.; Xie, J. Y.; Xu, N. X.; Li, Y. Electrochem. Commun., 2002, 4(6): 499

13 Ji, X. L.; Lee, K. T.; Nazar, L. F. Nature Materials, 2009, 8: 500

14 Zhang, Y.; Zheng, W.; Zhang, P.; Wang, L. Z.; Xia, T. C.; Hu, X. G.; Yu, Z. X. J. Wuhan University of Technology, Mater. Sci. Ed., 2007, 22(2): 234

15 Lai, C.; Gao, X. P.; Zhang, B.; Yan, T. Y.; Zhou, Z. J. Phys. Chem. $C, 2009,113(11): 4712$

16 Zhang, B.; Lai, C.; Zhou, Z.; Gao, X. P. Electrochim. Acta, 2009, 54(14): 3708

17 Oyama, N.; Tatsuma, T.; Sato, T.; Sotomura, T. Nature, 1995, 373 (6515): 598

18 Wang, W. K.; Wang, A. B.; Cao, G. P.; Yang, Y. S. Acta Phys. Chim. Sin., 2004, 20(12): 1440 [王维坤, 王安邦, 曹高萍, 杨裕 生. 物理化学学报, 2004, 20(12): 1440]

19 Zhang, Y. J.; Kong, L. B.; Zhan, L. Z.; Tang, J.; Zhan, H.; Zhou, Y. 
H.; Zhan, C. M. J. Power Sources, 2007, 168(1, Sp. ISS.SI): 278

20 Wang, J. L.; Yang, J.; Wan, C. R.; Du, K.; Xie, J. Y.; Xu, N. X. Adv. Funct. Mater., 2003, 13(6): 487

21 Yu, X. G.; Xie, J. Y.; Yang, J.; Huang, H. J.; Wang, K.; Wen, Z. S. J. Electroanal. Chem., 2004, 573(1): 121

22 Jung, Y. J.; Kim, S. Electrochem. Commun., 2007, 9(2): 249

23 Kim, N. I.; Lee, C. B.; Seo, J. M.; Lee, W. J.; Roh, Y. B. J. Power Sources, 2004, 132(1-2): 209

24 Sun, J.; Huang, Y. Q.; Wang, W. K.; Yu, Z. B.; Wang, A. B.; Yuan, K. G. Electrochim. Acta, 2008, 53(24): 7084

25 Sun, J.; Huang, Y. Q.; Wang, W. K.; Yu, Z. B.; Wang, A. B.; Yuan, K. G. Electrochem. Commun., 2008, 10(6): 930

26 Huang, Y. Q.; Sun, J.; Wang, W. K.; Wang, Y.; Yu, Z. B.; Zhang, H.; Wang, A. B.; Yuan, K. G. J. Electroanal. Soc., 2008, 155(10): A764

27 Wang, Y.; Huang, Y. Q.; Wang, W. K.; Huang, C. J.; Yu, Z. B.;
Zhang, H.; Sun, J.; Wang, A. B.; Yuan, K. G. Electrochim. Acta, 2009, 54(16): 4062

28 He, X. M.; Ren, J. G.; Wang, L.; Pu, W. H.; Jiang, C. Y.; Wan, C. R. J. Power Sources, 2009, 190(1): 154

29 Cheon, S. E.; Ko, K. S.; Cho, J. H.; Kim, S. W.; Chin, E. Y.; Kim, H. T. J. Electrochem. Soc., 2003, 150(6): A796

30 Cheon, S. E.; Ko, K. S.; Cho, J. H.; Kim, S. W.; Chin, E. Y.; Kim, H. T. J. Electrochem. Soc., 2003, 150(6): A800

31 Wang, J. Y.; Zhu, S. G.; Xu, C. F. Biochemistry (Vol.1). 3rd ed. Beijing: Higher Education Press, 2002: 123-196［王镜岩, 朱圣 庚, 徐长法. 生物化学(上). 第三版. 北京: 高等教育出版社, 2002 123-196]

32 Pejovnik, S.; Dominko, R.; Bale, M.; Gaberscek, M.; Jamnik, J. J. Power Sources, 2008, 184(2, Sp. ISS.SI): 593

33 Lou, G. Y.; Li, Y. M.; Cao, Y. Foundry, 2006, 55(5): 463 [娄桂艳, 李英明, 曹 阳. 铸造, 2006, 55(5): 463] 